\title{
Event order in language and cognition
}

\author{
Jürgen Bohnemeyer \\ Max Planck Institute for Psycholinguistics, Nijmegen
}

\section{Introduction}

The argumentation will proceed along the following lines:

With marginal exceptions, event order is not coded in Yukatek Maya: there are no deictic or anaphoric tenses, and no temporal connectives translating 'after' or 'before'. Instead, time reference and temporal coherence rely heavily on defeasible inferences from aspectual and modal information.

However, the outcomes of the Tемpest (short for Temporality Elicitation Stimulus) study, a referential communication task with a video stimulus, show that speakers of Yukatek are just as capable of identifying, categorising and communicating the order of events in the TемPEst videos as are speakers of German. Both groups of consultants scored about equally on the task, despite the fact that the German subjects coded event order in $92 \%$ of their reference acts, whereas the Yukatek subjects did so in just about $1 \%$ of their reference acts.

These results suggest that the temporal inferences derived from aspectual (and modal) information are Generalised Conversational Implicatures, i.e. they are defeasible default interpretations. It follows that event order relations are not semantic universals, but also, that cognitive representations of event order do not in their existence depend on semantic representations of event order.

\section{Prerequisites: Event Order}

What is meant by event order relations? In a nutshell, event order relations are twoplace semantic relations that locate an event on the time axis with respect to another event or to the moment of utterance. The examples (1) through (4) illustrate anterior event order. In (1), the conjunction before expresses anterior ordering of the reading event with respect to the temporal clause event (cf. e.g. Heinämäki 1974). In (2), the simple past tense marks anteriority of the reading event with 
respect to coding time. In (3), at least according to the traditional analysis of Reichenbach (1947), the pluperfect marks anteriority of the reading event with respect to the event expressed in the first sentence. This is what is commonly called 'relative' or 'anaphoric tense', as opposed to the 'absolute' or 'deictic tense' in (2) (cf. Comrie 1985). In (4), anaphoric anteriority is coded by the adverb beforehand.

(1) Temporal connectives

She read the paper before she had breakfast.

(2) Deictic/absolute tense

She read the paper.

(3) Anaphoric/relative tense

I reached the institute at 10.30 a.m. She had (already) read the paper.

(4) Anaphoric connectives

We discussed the paper over lunch. She read it beforehand.

Yukatek has none of these kinds of expressions. Instead, the communication of event order relies heavily on inferences from aspectual and modal information. ${ }^{1}(5)$ illustrates such inferences with English examples. The simple past tense forms in $(5 \mathrm{a}, \mathrm{b})$ represent the events as 'bounded' or 'completed', like a perfective aspect. Consequently, it is inferred that the events do not overlap, or that they are ordered sequentially. The precise order, however, is inferred to be iconically represented by the order of mention, as is apparent from the contrast between $(5 a, b)$. The progressive tense in (5)c represents the writing event as 'unbounded' or 'ongoing', and from this, it is inferred that this event overlaps with the bounded events referred to by the simple past tense forms in the following sentences.

(5) a. Temporal inferences: From boundedness to sequential order I wrote a paper. She read it. We discussed the issue.

b. Temporal inferences: Iconic representation of sequential order We discussed the issue. I wrote a paper. She read it.

c. Temporal inferences: From unboundedness to overlap I was writing a paper. She read a draft. We discussed the issue.

\section{The problem: Universalist and relativist views of the relationship between cognitive and linguistic representations}

The angle from which the issue of event order in Yukatek is approached in Bohnemeyer (1998) is the struggle between universalist and relativist views on the relationship between semantic representations and cognitive representations. Universalists argue that semantic representations of event order should be universal (meaning coded in every language) because they reflect cognitive representations of event order. A typical representative of this view is Alverson (1994), who argues: 
' (...) if (a) the experience and therefore the linguistic expression of crude space is universal (invariant across languages/cultures) and if (b) the process of typifying non-spatial experiential domains in terms of spatial ones is invariant across languages/cultures, then (c) the linguistic expression of the experience of time will also have a universal invariant component or aspect across languages and cultures.' (Alverson 1994:38).

The most explicit claims concerning the universality of event order expressions have been made by Anna Wierzbicka. In the framework of her Natural Semantic Metalanguage program, Wierzbicka argues that when, after and before code universal semantic primitives. She says:

'Another basic meaning one would expect to be able to express in any language involves the concept of 'time' (WHEN). One would expect to be able to say the equivalent of 'When did it happen?' and 'It happened at this time'. (...) in addition to the semantically simple temporal adjunct 'at some time', there must be in any language some complex ones: 'at this time', 'at the same time', 'at some time before this time' and so on. (...) The pairs of elements BEFORE and AFTER, and UNDER and ABOVE are necessary to accommodate relational concepts in the temporal and locational domains, respectively.' (Goddard and Wierzbicka 1994:45-46)

In contrast, orthodox relativists, and first and foremost of course Whorf, argue that the absence of event order relations in the code of a language reflects the absence of mental representations of event order in the speakers of that language:

'After long and careful study and analysis, the Hopi language is seen to contain no words, grammatical forms, constructions or expressions that refer directly to what we call 'time' (...)' (Whorf (Carroll ed.) 1956:57-58)

'Hence, I find it gratuitous to assume that Hopi thinking contains any such notion as the supposed intuitively felt flowing of 'time', or that the intuition of a Hopi gives him this as one of its data.' (Whorf (Carroll ed.) 1956: 144-145)

It is argued in Bohnemeyer (1998) that although Yukatek may come closer to Whorf's idea of a language which does not represent time than Hopi actually does, mental representations of event order do not differ in an attestable way across speakers of Yukatek and Indo-European languages. In effect, I submit that both universalism and relativism fall short of recognizing the difference between semantic representations and pragmatic representations. Speakers of Yukatek entertain cognitive representations of event order and successfully communicate these without having to code them in truth-conditional semantic representations. 


\section{The Yukatek data}

Let us take a brief look at the Yukatek data. Yukatek does not have absolute tenses, that is, the morpho-syntactic form of a clause does not reveal whether the clause refers to a time in the present, past or future of coding time. Take for example clauses formed with the so-called 'terminative' aspect marker $t s^{\prime} o^{\prime} k$. This is a poststate aspect, much like the English perfect. In (6a), this marker is used to refer to the post-state of the death of a child ('the baby had already died'). This post-state is itself located in the past of coding time. In (6b), however, $t s^{\prime} o^{\prime} k$ is used to refer to the post-state of an errand which is understood to be located in the future of coding time. In other words, $t s^{\prime} o^{\prime} k$ translates a present perfect, but just as well a pluperfect or a future perfect, depending on the context.

(6) a. Terminative aspect marker $t s^{\prime} o^{\prime} k$ with past time reference ${ }^{2}$

K-u k'uch-ul-o'b-e', ts'o'k u kim-il le chàampal-e'.

IMPERF-A.3 arrive-INCH-3.PL-TOP TERM A.3 die-INCH DEF small:child-D3

'(By the time) they arrived, the baby had already died.'

b. Terminative aspect marker $t s^{\prime} o^{\prime} k$ with future time reference

Sáamal óok-a'n+k'ìin-e' ts'o'k u bèet-ik le

tomorrow enter-RES+sun-TOP TERM A.3 do-INCH(B.3.sG) DEF

túus+bèel-o'

send+way:REL-D2

'By tomorrow at dusk (the boy) will have done the errand.'

(Andrade 1955: 135-136)

$T s^{\prime} o^{\prime} k$ does evidently not code a deictic tense relation. The question is now, can it be said to express 'relative' tense, such as the English pluperfect and future perfect, on Reichenbach's (1947) classical account? For example, in (6a), it might be argued that $t s^{\prime} o^{\prime} k$ marks relative anteriority of the child's death with respect to the arriving event. The counter argument here is that $t s^{\prime} o^{\prime} k$ is not compatible with time locational specifications that refer to the time of the event itself. For example, in (6b), sáamal óoka'n k'ìn 'tomorrow at dusk' does not refer to the time of the errand, but to a time at which it is asserted that the errand will already be in the post-state of its accomplishment.

If, on the other hand, the time of the event itself is to be specified, then $t s^{\prime} o^{\prime} k$ has to be replaced by the perfective aspect marker, as in (7). With terminative $t s^{\prime} o^{\prime} k$, the only available interpretation would be that the adverbial ho'lheak 'yesterday' does not refer to the time at which the addressee met the speaker's brother, but to a time at which the addressee was in the state of having met the speaker's brother, as in (8), which renders the question pragmatically odd. The incompatibility with event time specifications unequivocally identifies $t s^{\prime} o^{\prime} k$ as a marker of post-state aspect, ${ }^{3}$ not as a relative anterior tense. This illustrates one of the chief criteria 
employed in Bohnemeyer (1998) to test possible relative tense analyses, with the upshot that there is no expression of relative tense in Yukatek.

(7) Perfective aspect with event-time adverbials (compatible)

T-aw il-ah in suku'n ho'lheak, he'bix t-a

PRV-A.2 see-CMP(B.3sg) A.1sg elder.brother yesterday like PRV-A.2 tukul-ah-e'?

think-CMP(B.3.sG)-D3

'Did you meet my brother yesterday, as you had planned?' (Tama 45)

(8) Terminative aspect with event-time adverbials (incompatible)

?? Ts'o'k aw il-ik in suku'n ho'lheak?

TERM A.2 see-CMP(B.3.sG) A.1.sg elder.brother yesterday

'Were you yesterday in the state of having met my brother?'

Yukatek likewise lacks temporal connectives expressing event order, such as after or before. There are, however, temporal connectives, but these once again have aspectual meanings. One example is the connective káa that introduces each of the clauses in (9):

(9) a. Implicated event order with the perfective connective káa: sequential order with coreferential subjects

Pedro-e' káa t-u ts'íib-t-ah hun-p'éel kàarta-e',

Pedro-TOP káa PRV-A.3 write-APPL-CMP(B.3.sG) one-CL.IN letter-TOP

káa t-u ts'u'ts'-ah hun-p'éel chamal.

káa PRV-A.3 suck-CMP(B.3.sG) one-CL.In cigarette

'Pedro, (when) he wrote a letter, he smoked a cigarette.' (Default interpretation: sequential)

b. Implicated event order with the perfective connective káa: simultaneous order with non-coreferential subjects

Káa t-u ts'íib-t-ah hun-p'éel kàarta Pedro-e',

káa PRV-A.3 write-APPL-CMP(B.3.sG) one-CL.IN letter Pedro-TOP

Juán-e' káa t-u ts'u'ts'-ah hun-p'éel chamal.

Juán-TOP káa PRV-A.3 suck-CMP(B.3.sG) one-CL.IN cigarette

'(When) Pedro wrote a letter, Juán smoked a cigarette.' (Default interpretation for four out of five consultants: simultaneous)

Káa occurs exclusively with perfective aspect and serves to disambiguate the meaning of the perfective aspect marker, which covers both a bounded reading (as in 'the car broke') and a post-state reading (as in 'the car is broken'). The connective káa forces the bounded reading. This may spell out sequential order, as in (9a) 'Pedro wrote a letter and smoked a cigarette', but this is no more than an implicature. In (9b), which differs from (9a) in that the two clauses have different subjects ('Pedro wrote a letter, and Juan smoked a cigarette'), it is still understood that both events are bounded, or completed, but this time, it is inferred that the two events occurred simultaneously. Notice also that in (9b), káa might be analysed as a 
'general' temporal connective such as when or then, which does not specify a particular event order, but only indicates that the time of the main clause is somehow determined with respect to the time of the subordinate clause. (9b) would then read something like 'when Pedro wrote the letter, then Juan smoked a cigarette.' This analysis is, however, excluded by (9a), where the reference time of the second clause is shifted with respect to that of the first clause, rather than to be determined with respect to it.

Now, there is a number of principled exceptions to the claim that Yukatek lacks expressions of event order. First of all, there are the two adverbs (called 'topic time shifters' in Bohnemeyer 1998) be'ora ...-a'-e' and $k a^{\prime} c h(i l)$ that roughly translate 'now' and 'formerly'. These express simultaneity and anteriority with respect to coding time, just as absolute tenses would. However, the pragmatics of these adverbs is rather different from the pragmatics of Indo-European tenses. For example, $k a^{\prime} c h$ 'formerly' is used only in case a state that held at some point prior to coding time does not hold any longer at coding time, or in case an event that was about to happen at some time prior to coding time did then end up not happening at all.

Furthermore, there are five terms that determine days by their distance from the day of utterance: ka'ho'lheak 'the day before yesterday', ho'lheak 'yesterday', behe'la' ...-e'/-a' 'today', sáamal 'tomorrow' and ka'beh 'the day after tomorrow'. These are for calendrical reference, and of course, Yukatek has an entire system of calendrical terms for the hour, weekday, month and so forth (mostly borrowed from Spanish) which do not affect the claim about event order relations, since an expression such as Wednesday or 1805 does not really have to be analyzed as incorporating an event order relation. The terms for 'yesterday' and so forth are just special in that they cannot be defined without reference to event order; for example, 'yesterday' simply means the day before the day of utterance.

Finally, there are some complex expressions which serve as 'general' temporal connectives, i.e. they merely indicate that an utterance is asserted for a time determined in context, such as English 'when', or 'at that moment', without coding a specific event order relation. However, these phrases are quite infrequent in discourse. During the TEMPEST sessions, Yukatek speakers produced such expressions in just $1 \%$ of their reference acts, and these actually represent the only instances of event order coding in the entire Yukatek TемPEst corpus. Incidentally, Yukatek does not show an interrogative 'when' that could be used in questions to any location in time, but only complex constructions such as 'what hour?', 'what day?' that are used in questions for calendrical specifications.

Notice that none of the expressions discussed here is capable of coding the precise order of two events both of which are referred to in discourse. So the Whorfian hypothesis with respect to Yukatek could be rephrased as 'Since it is not the case that the exact order of any two events expressed in discourse can be coded in Yukatek, it is not the case that the order of events in discourse is mentally 
represented in speakers of Yukatek'. This hypothesis is in line with the facts about Yukatek code, but, as will be shown below, it is not line with what can be established about the mental representation of event order in speakers of Yukatek. As for Wierzbicka's hypothesis, the items mentioned above are too specific to be considered embodiments of the proposed semantic primitives 'after', 'before' and 'when'.

\section{The Tempest study}

The principal research questions of the TEMPEST study are the following:

- In communicating the same event orders, do speakers of Yukatek and German equally code event order?

- Are speakers of Yukatek and German equally successful in identifying, categorizing and communicating the same event orders?

The idea of the TемPEst study was to come up with a non-verbal representation of event orders in video clips, show these to speakers of Yukatek and of an IndoEuropean language (for which German was selected), then give the subjects a task of referential communication that forces them to try to convey the order of events in the videos as precisely as possible, see what linguistic expressions they would use to this end, and, in order to assess possible differences in the mental representation of event order across speakers of the two languages, see whether the two groups would differ in the successfulness with which they solve the task.

In manufacturing the TeMPEST videos, a special editing technique was used that allowed me to show in different videos exactly the same events, but in different orders. This way, 28 pairs of short video clips were created, three of which are schematically represented in Figure 1.

For example, in the first pair of clips in Figure 1, one character writes a letter and then bounces a basketball, and another character enters the room at some point and inflates a balloon which eventually bursts. In the first clip, the second character enters while the first character is writing the letter, and the balloon pops while the first character is playing with the ball, whereas in the second film, the ballooninflating character enters later, at a time when the writer is already playing with the ball, and the balloon pops while the ball is still being played.

Around this stimulus, a task of referential communication was devised that would force two subjects in each session to talk about the videos so as to distinguish them, which could only be done by establishing the difference in event order, as the minimal difference in event order constituted the only difference between the videos in each pair. The design of this task is schematized in Figure 2.

Let us call the two subjects of each session according to their roles in the session describer and identifier, respectively. First, the film to be singled out would be 

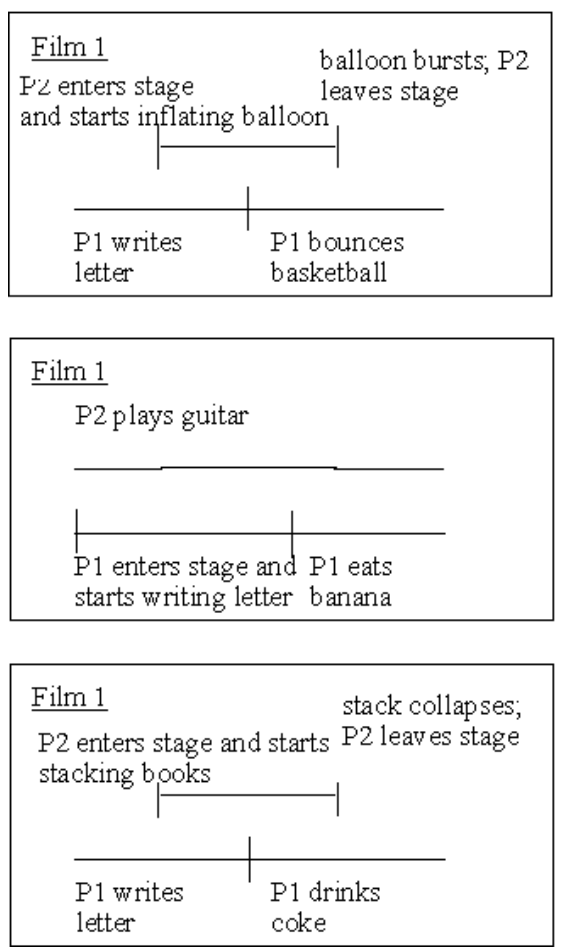
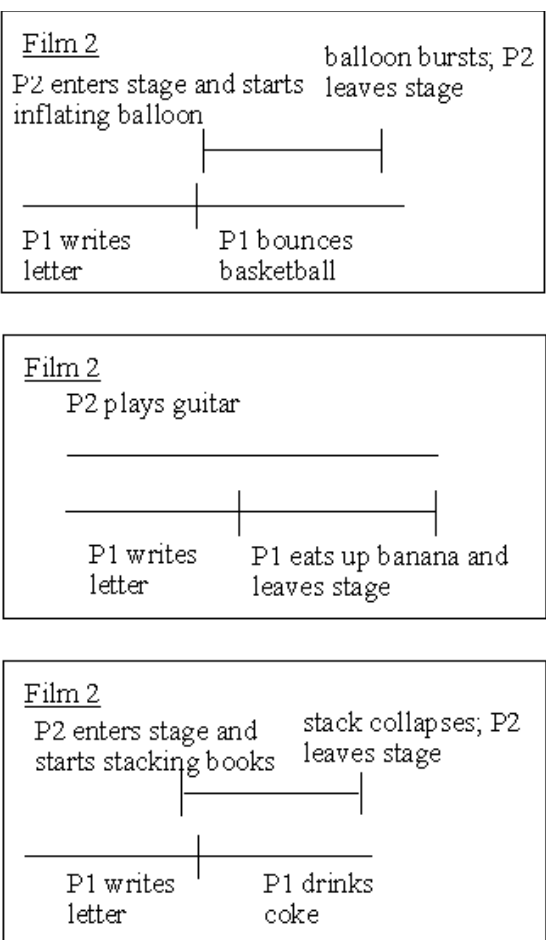

Figure 1. Structure of the Tempest stimulus (examples)

shown to the identifier. Then both films would be shown to the describer. The describer was then to state the difference between the two films she had seen. Next, the describer was to ask the identifier a yes-no question in order to determine which of the two films was the one the identifier had seen. For example, the describer would ask 'In the film that you saw, did the balloon pop after the whitedressed character wrote the letter?' The identifier would answer this question with a 'yes' or a 'no', the describer would infer from this answer which of the two films the identifier had seen, and would state her conclusion saying 'first film' or 'second film?.

The set-up that was used in carrying out the Tемpest task is sketched in Figure 3. A turnable video monitor was used so that the describer could not see which video the identifier was seeing, and the identifier would not know in which order the two videos were presented to the describer. With this set-up, the entire set of 28 pairs of video clips was shown to five pairs of adult native speakers of Yukatek and five pairs of adult native speakers of German.

The results, in terms of the types of expressions used by the two groups of consultants, are diagramed in Figure 4. 
Activities on the part of the Describer (D)

Step 2: Both films in the pair are shown to $D$

Step 3: D describes the difference between the two films (s)he has seen

\section{Activities on the part of the Identifier (I)}

Step 1: the target film (i.e. the film to be identified) is shown to I

Step 4: D asks a yes-noquestion about the target film

Step 6: D infers from I's

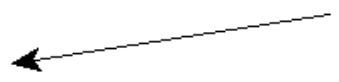
answer which of his/her two films is the target film

Figure 2. Design of the Tempest task

The dotted bar represents specific event order connectives such as after and before. Yukatek speakers did not use such expressions at all. This does not come as a surprise, as we already know that Yukatek does not have specific event order connectives. However, even the German consultants used specific event order connectives in no more than $24 \%$ of their reference acts. In the far majority of instances, namely in $68 \%$ of the cases, the German speakers used just a general temporal connective, represented by the shaded bar. They would say, for example, not 'Did the balloon pop after the white-dressed character wrote the letter?', but instead 'Did the balloon pop when the letter was already finished?'. We saw that Yukatek does show such general temporal connectives too. However, as the little shaded bar at the bottom of the Yukatek column shows, even those were used by the Yukatek consultants in just about 1\% of their reference acts. In $99 \%$ of the Yukatek reference acts, event order was not coded at all, but left to inferences from aspectual information and order of mention, as represented by the hatched bar. This as opposed to just $8 \%$ of the German reference acts that relied entirely on such inferences. So it is indeed fair to say that German speakers coded event order in the overwhelming majority of cases, whereas Yukatek speakers left event order to defeasible inferences in the overwhelming majority of cases. 


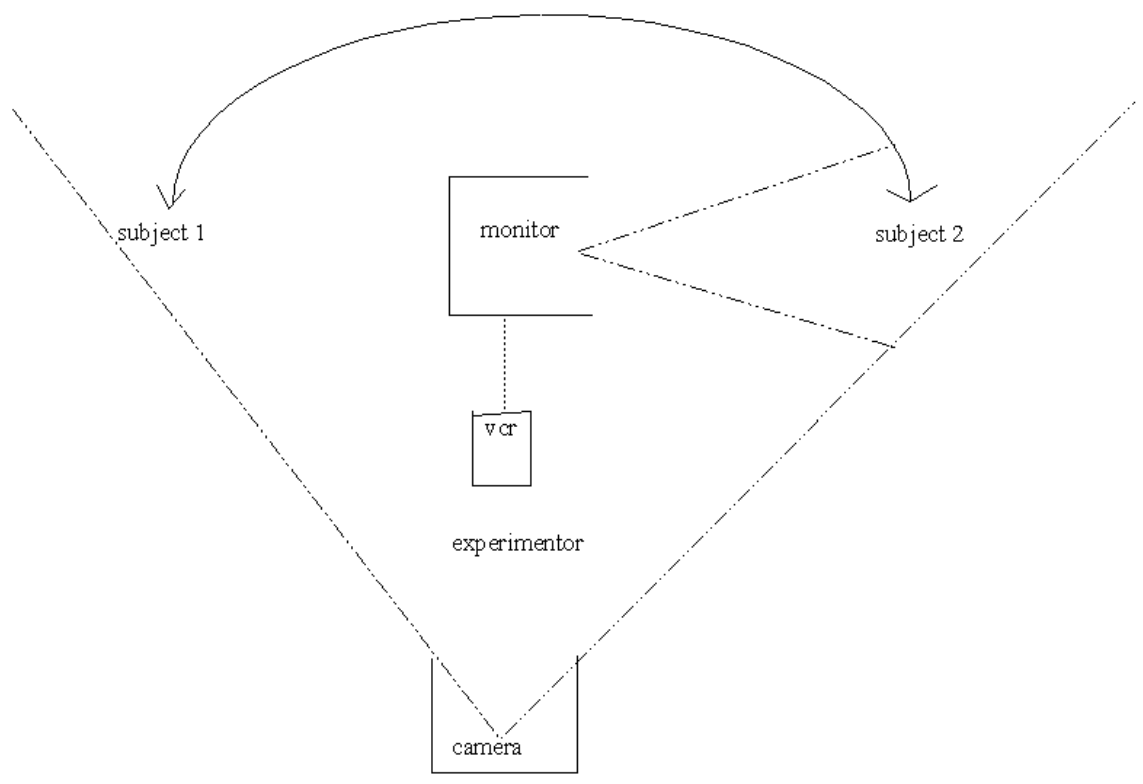

Figure 3. Setup of the Tempest sessions

Let us now turn to the error rates, as presented in Figure 5. Evidently, they were practically identical across both groups of consultants. In terms of the absolute numbers of errors, there were just slightly more errors on the part of the German subjects (20 as opposed to 19), while in terms of the number of runs during which errors occurred, the Yukatek subjects committed slightly more errors (18 unsuccessful runs as opposed to 16 with German speakers). The latter figures are represented here, the hatched bars stand for the successful runs and the dotted bars for the unsuccessful runs. Either way, the difference in the error rates is insignificant.

These results indicate the following: In communicating the same event orders, speakers of German code event order pervasively, whereas speakers of Yukatek do so only marginally. Yet, speakers of both languages manage to cognize and communicate these event orders with about equal success. There is no observable difference in the mental representation of the event orders across speakers of the two languages. This means that the successfulness with which Yukatek speakers communicate event order based on inferences from aspectual (and modal) information requires an account of these inferences that explains their generality and reliability. 


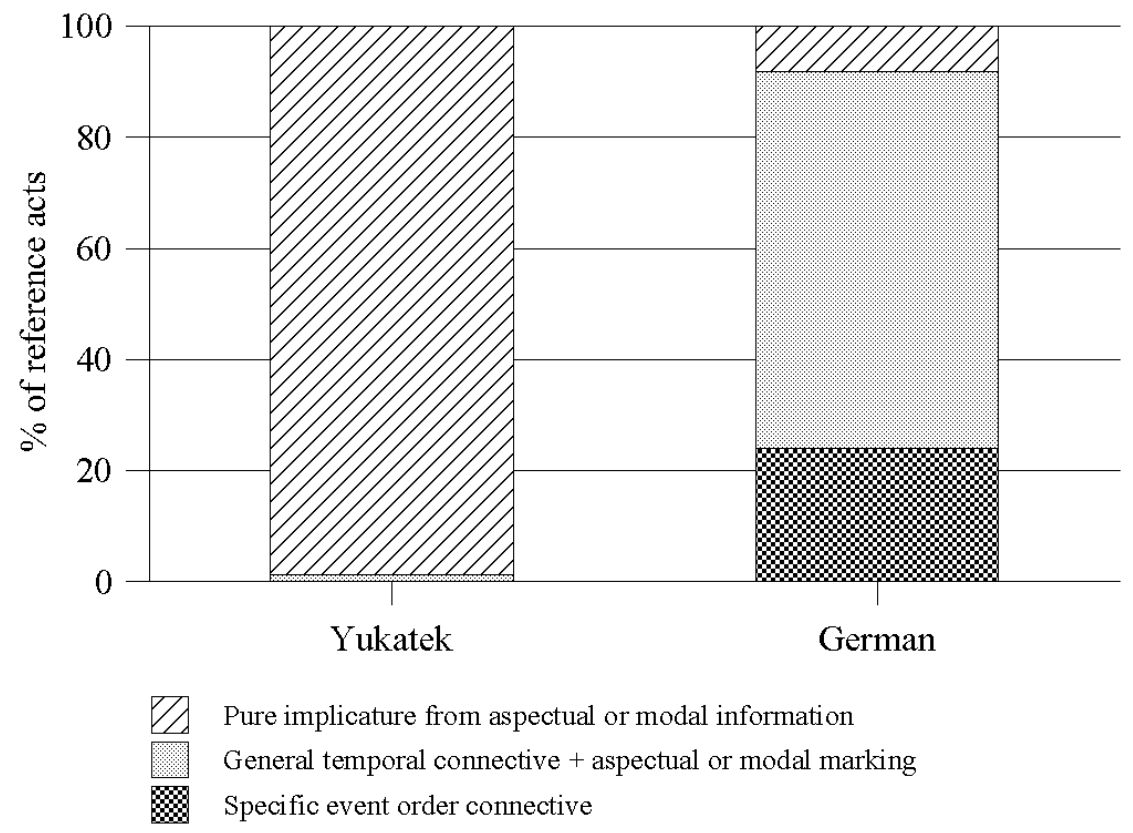

Figure 4. Results of the TEMPEST sessions: the expression of event order

\section{A Radical Pragmatics approach to event order in discourse}

In order to account for the generality and reliability of inferences from aspectual information to event order, Bohnemeyer $(1998,2000)$ proposes a theory that treats these inferences in terms of Gricean Generalized Conversational Implicatures (cf. Grice 1975). Let us first take a look at the kind of inferences this account has to deal with. (10) exemplifies an inference from unboundedness to overlap.

(10) Unboundedness to overlap

John entered Mathilda's office. Mathilda was dozing at her desk.

$+>$ J. entered overlapping with M.'s sleeping.

Unboundedness of Mathilda's dozing at her desk is marked by the progressive. It is inferred that John's entering overlaps with Mathilda's sleep. (11) invites an inference from boundedness to non-overlap, or sequential ordering.

(11) Boundedness to non-overlap

John entered Mathilda's office. He lit a cigarette.

$+>$ J. lit the cigarette consecutively to his entering of M.'s office. 


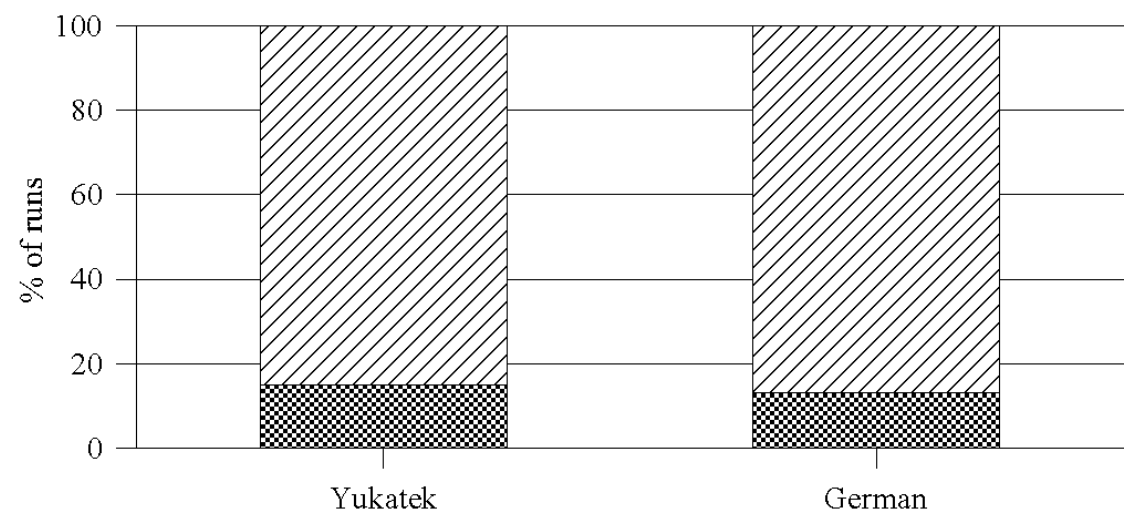

$\forall$ Successful runs $\$$ Unsuccessful runs

\begin{tabular}{|l||r|r|}
\hline Unsuccessful runs & 18 & 16 \\
\hline Successful runs & 102 & 106 \\
\hline
\end{tabular}

Figure 5. Results of the TемPEST sessions: error rates

The simple past forms represent the events as bounded or completed, like a perfective aspect. Finally, (12) illustrates an inference from ingression to overlap.

(12) Ingression to overlap

Mathilda started reading the paper. John entered her office.

$+>\{$ J. entered the office subsequent to M.'s starting reading $+>$ J. entered the office overlapping with M.'s reading.\}

It is inferred that John entered Mathilda's office after Mathilda started reading, and that Mathilda was reading at the moment John entered. These are three out of a set of six types of inferences from aspectual information to event order. Why just these six? This set of inferences is grounded in the assumption that there are six 'logical' or 'notional' types of aspectual operators, or as they are called in Bohnemeyer (1998), boundary operators. Perfective aspects represent the event as bounded or completed, in other words, within its boundaries. Imperfective or progressive aspects represent the event as unbounded or ongoing, in other words, abstracting from its boundaries. Ingressive and egressive operators select the initial or terminal boundary of the event for assertion; examples are 'phase verbs' such as start, begin, stop, finish. Finally, there are post-state operators such as perfects or resultatives and pre-state operators such as the be going to construction of English and its likes in Romance languages. Each of these notional boundary operators introduces a different viewpoint on the event (cf. Comrie 1976; Holt 1943; Smith 1991). This is 
illustrated for perfective and imperfective operators in Figure 6 and for the other notional aspects in Figure 7.
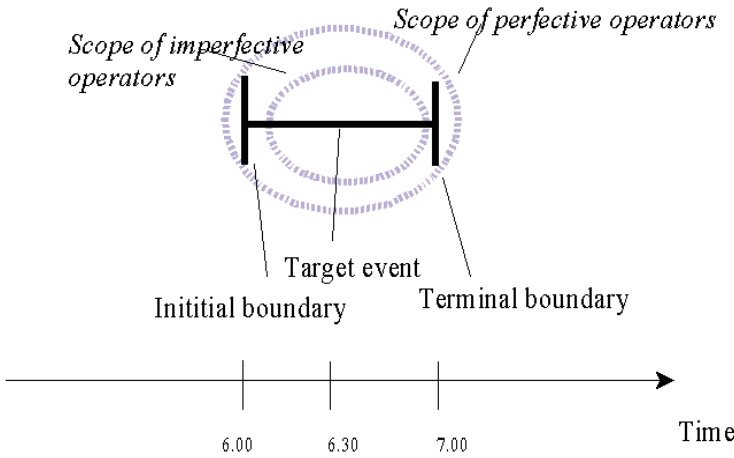

Figure 6. Rationale of the boundary-to-order implicatures: perfective and imperfective viewpoints on the event

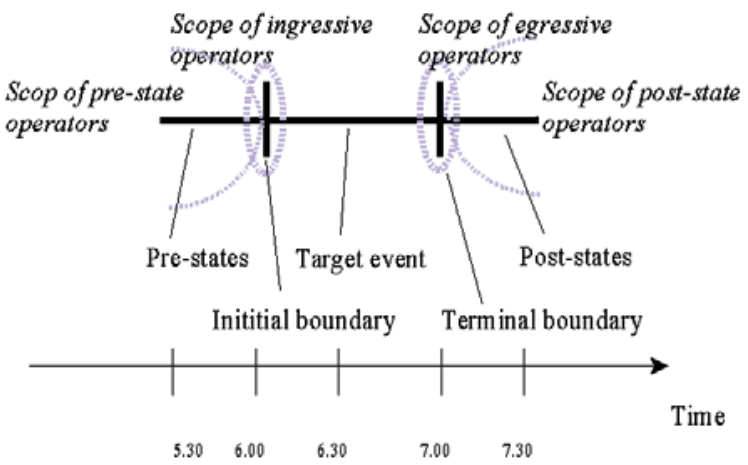

Figure 7. Rationale of the boundary-to-order implicatures: other viewpoints on the event

Each of the six aspectual viewpoints implicates a different event order. For example, if the post-state of an event is referred to, this post-state is asserted for a time that follows the event, and it will be implicated that this time is the time of another event which accordingly follows the first event in time. Therefore, to the six notional boundary operators a set of six principled boundary-to-order (BTO) inferences can be assigned.

Now why is it that BTO inferences are Generalised Conversational Implicatures? Firstly, because they are default interpretations (cf. Levinson 1995, 2000). 
That is, in examples such as (10), (11), and (12) above, no speaker of English fails to derive the particular inferences, and this in the absence of any information about the speaker's intention or the non-linguistic context of the utterances. But secondly, boundary-to-order inferences are defeasible. For example, they can be canceled by expanding the context. Thus, in (13), the inference that John's entering overlapped with Mathilda's sleeping is canceled by an utterance saying that John's opening the door caused Mathilda to wake up. Under cancellation, the temporal implicature evaporates without leaving a contradiction.

(13) Defeasibility of the inference from unboundedness to overlap John entered Mathilda's office. Mathilda was dozing at her desk. She woke up when John opened the door.

$\Rightarrow$ M.'s dozing did not overlap with J's entering.

(14) Defeasibility of the inference from boundedness to non-overlap John entered Mathilda's office. He lit a cigarette, had a deep pull, pushed the door open and yelled 'Hi, I'm back'.

$\Rightarrow \mathrm{J}$. did not light the cigarette after entering the office.

(15) Defeasibility of the inference from ingression to overlap Mathilda started reading the paper. John entered her office. When he pushed the door open, $\mathrm{M}$. had just put the paper down in order to make a phone call. $\Rightarrow \mathrm{M}$. was not reading while J. entered.

\section{Conclusions}

Three principled conclusions can be derived from this study:

First of all, event order relations are not semantic universals. In particular, there are no expressions in Yukatek that would allow to code the order of any random pair of two events in discourse. This directly falsifies the universalist hypothesis.

Secondly, the mental representation of event order in the speakers of a language does not attestably depend on whether the language provides expressions of event order. Despite the fact that German subjects coded event order pervasively during the Tempest sessions while Yukatek subjects did so only marginally, both groups of consultants solved the Tempest task with equal successfulness. This does not support the relativist hypothesis.

The reason both the universalist and the relativist position fail to account for the Yukatek facts is that both assume a direct interdependence between cognitive and semantic representations, neglecting the difference between semantic and pragmatic representations.

Finally, all event order configurations can be defeasibly, but reliably and predictably inferred from aspectual information through Generalized Conversational Implicatures. 


\section{Notes}

1. Temporal inferences rooted in aspectual information have attracted much attention in particular since Partee 1973. Cf. Bach 1981; Boogaart 1999; Caenepeel and Moens 1994; Dowty 1986; Hinrichs 1981, 1986; Kamp 1979; Kamp and Rohrer 1983; Kamp and Reyle 1993: Ch. 5; Lascarides 1990; Lascarides and Asher 1992, 1993; Moens 1987; Moens and Steedman 1986; Partee 1984; Sandström 1993; ter Meulen 1995, and others.

2. Abbreviations in interlinear morpheme glosses include the following: 1/2/3-First/Second/Third Person; A - Cross-reference Set A ('ergative', possessor); APPL — Applicative; B - Crossreference Set B ('absolutive'); CL — Classifier; CMP — Completive; D2 - Distal; D3 — Textual deixis; DEF - Definite determiner; IMPERF - Imperfective; IN — Inanimate; INC — Incompletive; PL — Plural; PRV — Perfective; REL — Relational; RES — Resultative; SG — Singular; TERM Terminative; тор — Topic

3. Cf. Bohnemeyer (1998:71-86), following, with slight modifications, Klein (1994: 109-117).

\section{References}

Alverson, H. (1994) Semantics and experience: universal metaphors of time in English, Mandarin, Hindi, and Sesotho. Hopkins University Press, Baltimore.

Bach, E. (1981) 'On Time, Tense, and Aspect: An Essay in English Metaphysics'. In P. Cole, ed., Radical Pragmatics. Academic Press, New York etc., 63-82.

Bohnemeyer, J. (1998) Time Relations in Discourse. Evidence from a comparative approach to Yukatek Maya. Doctoral dissertation. Katholieke Universiteit Brabant, Tilburg.

Bohnemeyer, J. (2000) 'Where do pragmatic meanings come from? The source of temporal inferences in discourse coherence'. In W. Spooren, T. Sanders and C. van Wijk, eds., Samenhang in diversiteit. Opstellen voor Leo Noordman [Unity in diversity. Papers presented to Leo Noordman]. Katholieke Universiteit Brabant, Tilburg, 137-153.

Boogaart, R. (1999) Aspect and temporal ordering. A contrastive analysis of Dutch and English. Doctoral dissertation. Vrije Universiteit, Amsterdam.

Caenepeel, M. and Moens, M. (1994) 'Temporal structure and discourse structure'. In C. Vet and C. Vetters, eds., Tense and aspect in discourse. De Gruyter, Berlin etc., 5-20.

Comrie, B. (1976) Aspect. An introduction to the study of verbal aspect and related problems. Cambridge University Press, Cambridge etc.

Comrie, B. (1985) Tense. Cambridge University Press, Cambridge.

Dowty, D.R. (1986) 'The Effects of Aspectual Class on the Temporal Structure of Discourse: Semantics or Pragmatics?.' Linguistics and Philosophy 9, 37-62.

Goddard, C. and Wierzbicka, A. (1994) 'Introducing lexical primitives'. In C. Goddard and A. Wierzbicka, eds., Semantic and lexical universals: theory and empirical findings. Benjamins, Amsterdam etc., 31-54.

Grice, H. P. (1975) 'Logic and conversation'. In P. Cole and J. L. Morgan, eds., Speech Acts (Syntax and Semantics; 3). Academic Press, New York, 41-58.

Heinämäki, O.T. (1974). Semantics of English temporal connectives. Ph.D. dissertation, Austin: University of Texas.

Hinrichs, E. (1981) Temporale Anaphora im Englischen. MA Thesis, University of Tübingen.

Hinrichs, E. (1986) 'Temporal Anaphora in Discourses of English'. Linguistics and Philosophy 9, 63-82. 
Holt, J. (1943) Études d'aspect. Acta Jutlandica 15.2.

Kamp, H. (1979) 'Events, Instants, and Temporal Reference'. In R. Bäuerle, U. Egli and A. von Stechow, eds., Semantics from Different Points of View. Springer, Berlin etc.

Kamp, H. and Rohrer, C. (1983) 'Tense in Texts'. In R. Bäuerle, C. Schwartze and A. von Stechow, eds., Meaning, Use, and Interpretation of Language. De Gruyter, Berlin, 250-269.

Kamp, H. and Reyle, U. (1993) From Discourse to Logic. Introduction to Modeltheoretic Semantics of Natural Language, Formal Logic and Discourse Representation Theory. 2 vols., Kluwer, Dordrecht etc.

Klein, W. (1994) Time in language. Routledge, London etc.

Lascarides, A. (1990) Knowledge, causality and temporal representation. Research Report HCRC/ RP-8, Human Communication Research Centre, University of Edinburgh.

Lascarides, A. and Asher, N. (1992) 'Knowledge, causality and time'. Linguistics 30/5, 941-973.

Lascarides, A. and Asher, N. (1993) 'Temporal Interpretation, Discourse Relations and Commonsense Entailment'. Linguistics and philosophy 16, 437-493.

Levinson, S.C. (1995) 'Three Levels of Meaning'. In F. R. Palmer, ed., Grammar and Meaning. Essays in Honour of Sir John Lyons. Cambridge University Press, Cambridge etc., 90-115.

Levinson, S.C. (2000). Presumptive Meanings: The Theory of Generalised Conversational Implicatures. MIT Press, Cambridge, MA.

Moens, M. (1987) Tense, Aspect, and Temporal Reference. PhD thesis, University of Edinburgh.

Moens, M. and Steedman, M. J. (1986) Temporal Information and Natural Language Processing. Edinburgh Research Papers in Cognitive Science, 2, Edinburgh.

Partee, B. (1973) 'Some Structural Analogies Between Tenses and Pronouns in English'. The Journal of Philosophy 70, 601-609.

Partee, B. (1984) 'Nominal and Temporal Anaphora'. Linguistics and Philosophy 7, 243-86.

Reichenbach, H. (1947) Elements of symbolic logic. The Free Press, New York, and CollierMacmillan, London.

Sandström, G. (1993) When-clauses and the Temporal Interpretation of Narrative Discourse. $\mathrm{PhD}$ thesis. Umeå University.

Smith, C.S. (1991) The Parameter of Aspect. Kluwer, Dordrecht etc.

ter Meulen, A. G. B. (1995) Representing Time in Natural Language. MIT Press, Cambridge, MA, etc. Whorf, B.L. (1956) Language, thought and reality: selected writings of Benjamin Lee Whorf (ed. by J. B. Carroll). MIT Press, Cambridge, MA. 